\title{
PERMANENT INTERCONNECTION TECHNOLOGY
}

\author{
D. S. CAMPBELL \\ Electronic and Electrical Engineering Department, Loughborough University of Technology, \\ Loughborough, Leics., U.K. \\ and \\ D. BOSWELL \\ ITT Components Group, Paignton, Devon, U.K.
}

(Received June 2, 1980)

\begin{abstract}
This paper is concerned with the permanent connection of electronic components into sub-systems and is based on the report of an ERC Working Party that investigated the subject during 1978 and 1979. After an initial description of the interconnection concepts and the relationship the field has to electronic assembly systems in general, a survey is given of the marketing data that is available that defines the economic importance of the field. This survey includes new data obtained by the Working Party. Figures are given for the rest of Europe in general and the UK in particular and it is noted that the Output at Sales Value in the UK of interconnection technology products is almost the same as the Output at Sales Value of ICs in the UK. Within permanent interconnection technology two-thirds of the Output at Sales Value is associated with PWBs and one-third with thick/thin film circuits.

Research work in the field is discussed and a division between immediate time scale problems and those involving a longer time scale is suggested. Twenty-nine immediate time scale $R$ \& D problems have been recognized covering all three interconnection technologies; longer time scale problems will be associated with the continuing decrease in the size of add-on electronic components.

It is concluded that large, fast computer systems will require a decrease in the size and spacing of interconnections to match those of the semiconductor chip. This means simultaneous design of semiconductor and associated interconnection structures tasks well-suited to vertically integrated companies. In contrast, many real time subassemblies will benefit from greater chip complexity and need fewer outgoing leads per chip, i.e. at wider spacings - needs that can be met by the development of existing techniques. Finally it is suggested that future distribution of added value in electronic assembly operations is likely to give all sectors of interconnection business a steady upward sales trend, with both hybrid and semiconductor manufacturers seeking specialized subsystems markets to replace their present "all things to all customers" policies.
\end{abstract}

\section{INTRODUCTION}

The importance of interconnection systems for electronic components has recently been recognized in Government circles by the formation of a Working Party to look into the magnitude of the business involved and also to make recommendations as to the required research and development work needed to maintain or stimulate activity in the United Kingdom. After approximately two years study, the Working Party reported to the Electronic Research Council in March of this year (1980), and presented to Council a document entitled 'Permanent Interconnection Technology'. The report of the Working Party had been commissioned by the Materials Committee in cooperation with the Solid State Physics and Devices Committee. The report analysed the marketing data available and compared the data with figures obtained by the Working Party itself as the result of a confidential questionnaire, and also discussed the $\mathrm{R} \& \mathrm{D}$ work needed in the field, both in terms of medium term and longer term problems.

This paper summarizes the ERC report. After an initial description of the interconnection technology concept and the relationship the field has to electronic assembly systems in general, a survey is given of the marketing data obtained. The research and development activities considered of importance in the area is then discussed, and a division is made between activities that are of immediate importance to the well-being of the present industry and those longer term projects that may well imply a difference in philosophy. 


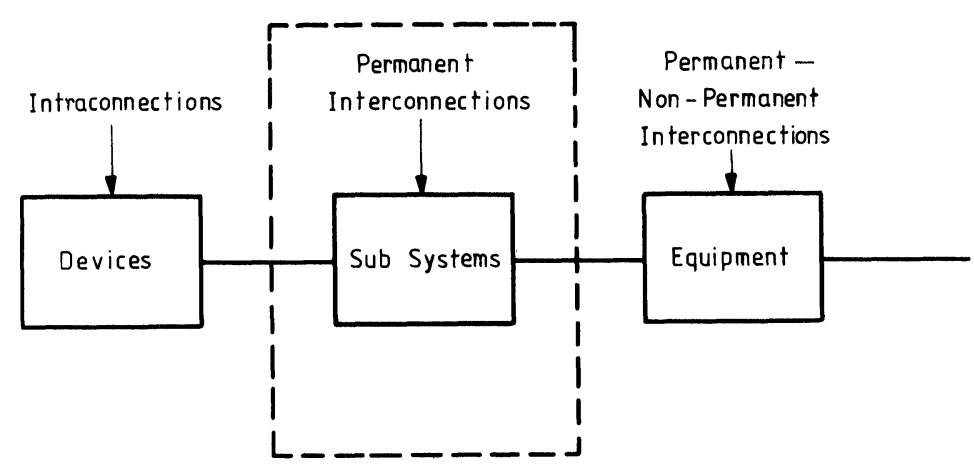

FIGURE 1 Relationship of Interconnection Technology to Device and system development.

\section{INTERCONNECTION TECHNOLOGY}

Permanent interconnection technology is concerned with the connection of electronic components into subsystems and total equipments. The components involved can be discrete passive and active devices of a simple or complex nature, and the connection system as such must be in a permanent form that does not easily lend itself to reworking and repair. The repair aspect of the definition means that wiring systems using wire, whether using soldered joints or wire wrapping, are not involved in the study, neither are plugs and sockets. The technology is, however, concerned with deposited systems, and includes Printed Wiring, ${ }^{1}$ Thick film, ${ }^{2}$ and Thin film ${ }^{3}$ techniques. These systems can also have the possibility of including passive components prepared within the interconnection system itself, such as the resistors prepared with Thick film methods and the resistors and capacitors made in Thin film.

Figure 1 defines the area covered by Permanent Interconnection technology. The progression in complexity from devices on the left of the diagram to equipment on the right indicates the relationship between the various levels of construction involved. Two things need to be added. Firstly by the term 'Devices' one includes VLSI ${ }^{4,5}$ as well as discrete monofunctional components, and therefore there is a high degree of complexity already possible in this area. Secondly, the permanent interconnections under consideration are mainly, but by no means exclusively, associated with the subsystems, and this is indicated by the dotted boundary around this area. However, the boundary is not fixed - there are permanent interconnection requirements in both the device and the equipment areas.

\section{MARKET DATA}

\subsection{Introduction}

In order to determine the economic importance of permanent interconnection technology, the working party spent some time in analysing the marketing data available. It found, initially, that the data was not complete enough or self consistent and, therefore, it was decided to obtain some independent figures by means of a questionnaire that was sent to a large number of relevant companies. The results of both the analysis and of the independent questioning are presented in this section.

\subsection{Background Data}

In order to make judgement of the importance of a particular technology, it is necessary to look at the size of the total markets involved. Table I gives the world market for electronic equipment in billions of dollars (Dollars $\times 10^{9}$ ) for '78 and '79. ${ }^{6}$ Table II, from the same reference, ${ }^{6}$ gives the figures for components alone. It is possible to obtain more detail for the figures of Table II, and these are given, in the case of W. Europe, in Table III. ${ }^{6}$ This table gives the figures for both the active and passive markets, with

TABLE I

World market for electronic equipment (after Ref.6.) (B\$)

\begin{tabular}{lccl}
\hline & '78 & '79 & $\%$ Growth \\
\hline W. Europe & 33 & 37 & 12 \\
U.S. & 68 & 77 & 13 \\
Japan & 20 & 23 & 15 \\
\hline
\end{tabular}


TABLE II

World market for components (after Ref.6.) (B\$)

\begin{tabular}{lrrl}
\hline & '78 & '79 & \% Growth \\
\hline W. Europe & 8.2 & 8.7 & 6 \\
U.S. & 10.7 & 11.7 & 9 \\
Japan & 7.8 & 8.4 & 8 \\
\hline
\end{tabular}

TABLE III

W. Europe market for components (after Ref.6.) (B\$)

\begin{tabular}{llll}
\hline & '78 & '79 & \% Growth \\
\hline Passive & 4.2 & 4.4 & 6.4 \\
Discrete Semi. & 1.0 & 1.0 & 3.4 \\
ICs & 1.2 & 1.3 & 11.9 \\
Opto electronics & 0.11 & 0.12 & 12.3 \\
Tubes & 1.8 & 1.8 & 4.2 \\
TOTALS & $\mathbf{8 . 2}$ & $\mathbf{8 . 7}$ & \\
\hline
\end{tabular}

the active market, with a total of $4.0 \mathrm{~B} \$$ for ' 78 and 4.3 B \$ for' 79 (growth of 6.4\%), being subdivided into four areas. Three points need to be made. Firstly, all the figures in the last three Tables have been given at constant 1978 values - i.e. the growth figures quoted are real increases. Secondly, the market figures are rounded whereas the \% increase values given have been calculated on the original data. Finally, it can be seen from Table III that the size of the passive component market is the same as the active market, with the growth rates also being the same.

Details of the passive component market in W. Europe are given in Table IV. ${ }^{6}$ In this table the seven largest passive component areas are noted together with the total component figure from Table III. Figures for one of the permanent interconnection technology methods now appear in Table III in the row for 'printed wiring boards'.

\section{TABLE IV}

W. Europe market for passive components (after Ref.6.) (B\$)

\begin{tabular}{lcc}
\hline & '78 & $' 79$ \\
\hline Capacitors. Fixed & 0.87 & 0.92 \\
Connectors & 0.58 & 0.64 \\
PWBs & 0.55 & 0.60 \\
Relays & 0.37 & 0.38 \\
Resistors. Fixed & 0.29 & 0.29 \\
Switches & 0.26 & 0.27 \\
Potentiometers & 0.24 & 0.25 \\
TOTAL (All components) & $\overline{8.21}$ & $\overline{8.74}$ \\
\hline
\end{tabular}

TABLE V

1979 production for ICs and PWBs for W. Europe countries (after Ref.7.) (M\$)

\begin{tabular}{lrc}
\hline & IC & PWB \\
\hline Austria & - & - \\
Belgium & 4 & 26 \\
Denmark & - & 14 \\
Finland & - & - \\
France & 105 & 91 \\
Italy & 124 & 16 \\
Netherlands & 34 & 11 \\
Norway & - & - \\
Spain & 5 & 14 \\
Sweden & 11 & 14 \\
Switzerland & 57 & 11 \\
U.K. & 211 & 85 \\
W. Germany & 364 & 94 \\
TOTAL & - & 367 \\
\hline
\end{tabular}

\subsection{Permanent Interconnection Technology Data}

Tables I-IV have given the background information available that defines the size of the total markets for equipment and components. Comparison can be made between the markets and production of interconnection systems and that of ICs and Table V gives such figures for ICs and PWBs for thirteen countries of W. Europe. ${ }^{7}$ It can been seen that for certain countries PWB production is greater than ICs. However, in the case of the two largest producers, the UK and W. Germany, the ratio of PWB to IC production is $1: 0.4$ and $1: 0.25$ respectively. PWBs can be manufactured in a variety of forms, and predictions have been made as to the sizes of these markets in $1982 .{ }^{8}$ Table VI gives these figures in the terms of 1978 values.

The data so far discussed has been in terms of the markets available or production. A figure that is also of interest in examining marketing information is that of Open Market or Open Market Usage, and the derived term Total Market Usage. The former term is defined as the national purchases, including imports,

\section{TABLE VI}

World PWB market in 1982 at 1978 values (after Ref.8.) (M\$)

\begin{tabular}{lr}
\hline Single sided & 200 \\
Double sided & 700 \\
Multilayer & 450 \\
Flexible & 180 \\
Others & 50 \\
TOTAL & 1580 \\
\hline
\end{tabular}




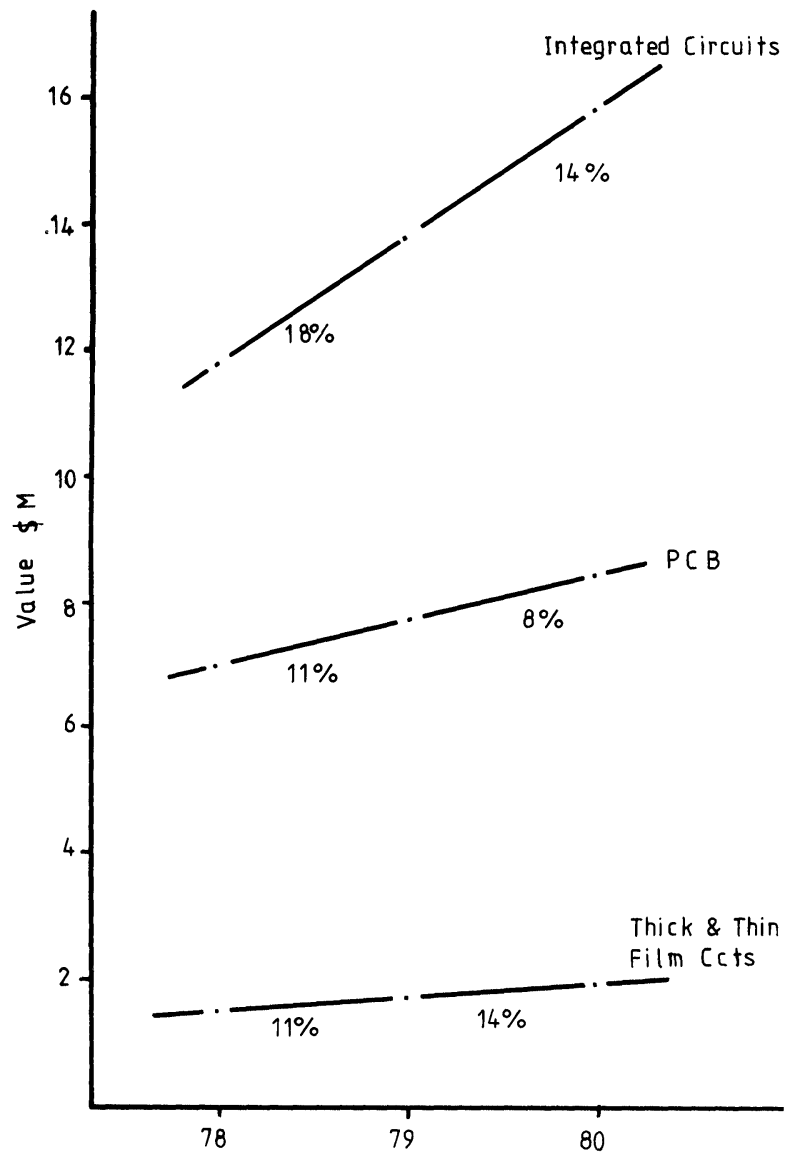

FIGURE 2 Total Market Usage of ICs., PWBs., and Thick and Thin film circuits in W. Europe (at November 1979 values). (After Ref. 9.)

and the latter is defined as the Open Market Usage plus the transfer value of home 'in-house' manufacture. Figure 2 gives such figures for W. Europe for not only ICs and PWBs but also for the other two permanent interconnection methods combined, namely Thick film and Thin film. ${ }^{9}$ These figures are at November 1979 values and give predictions made in 1979 of the expected 1980 values. Percentage growth values are noted between the relevant points.

Marketing data obtained from the Working Party questionnaire relates to the position in the UK. Output at Sales Value was one of the figures obtained and this is defined as the total national manufacture at sales value including 'in-house' output at transfer value. Such a figure includes direct exports. Output at Sales Value is shown over the last four years in Figure $3,{ }^{10}$ where the IC value is also shown for comparison. In Figure 3 the data is given for PWBs

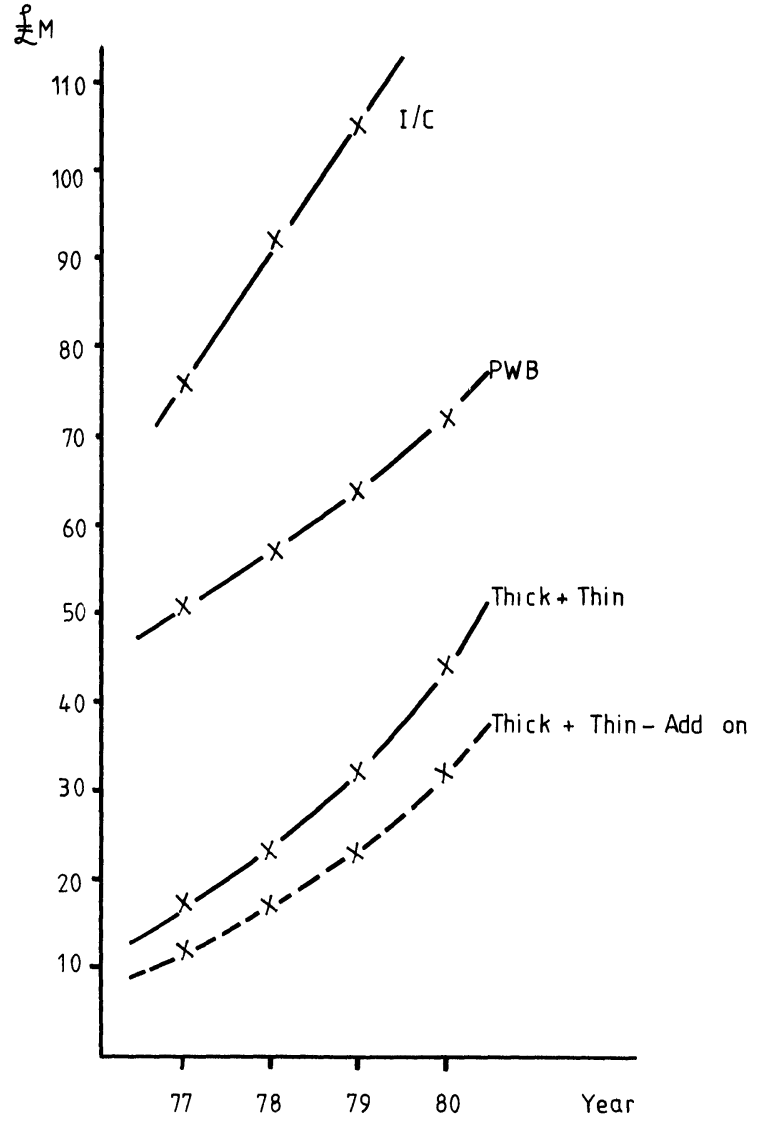

FIGURE 3 Output at Sales Value in the UK for ICs., PWBs., and Thick and Thin film circuits. (In the latter case showing the effect of add-on components.) (After Ref. 10.)

and for the sum of Thick film plus Thin film. It may seem inappropriate to compare in economic terms the manufacture of hybrid circuits (Thick film and Thin film circuits), with unpopulated PWBs. Hybrid circuits, by definition include add-on components and frequently represent operational modules performing specific electronic functions, whereas PWBs include none of the devices which will most certainly be added to them in succeeding stages of use. Nevertheless the Working Party has made such a comparison since the two products in the form described represent manufactured products as made in industry and as supplied at identifiable cost from one type of manufacturer to another. It is argued that the two major branches of the interconnection industry are structured in this way. Figure 3 gives the data assessed in this manner. If, however, one needs to compare the interconnection contribution in Thick and Thin film circuits with PWBs, where no add-on components are involved, the purchase price of the 


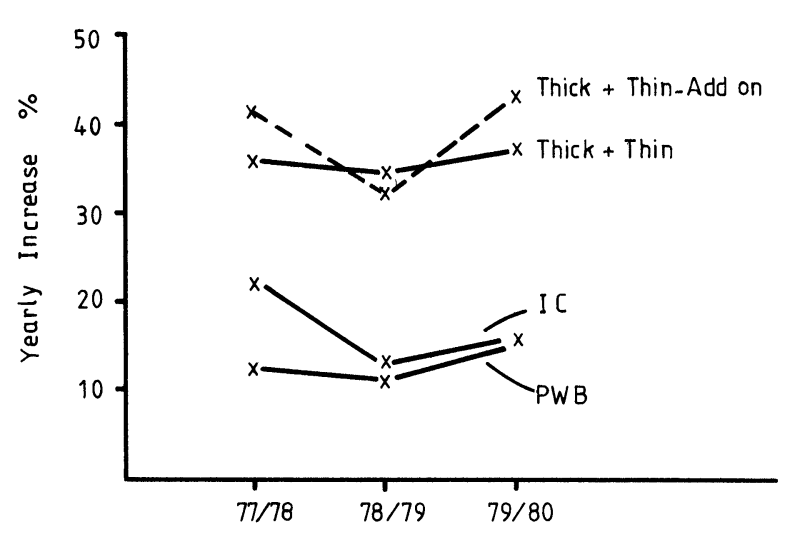

FIGURE $4 \%$ Increase in Output at Sales Value in UK (After Ref. 10)

add-on components in the Thick and Thin film circuits must be deducted from the output at sales value. Such data had been obtained by the Working Party and the resultant values are shown as the lowest curve in Figure 3. It is of interest to note that the effect of the add-on components is about $30 \%$ of the total Thick and Thin film circuit value.

Figure 4 gives the \% increase in Output at Sales Value for the data in Figure 3. These values have been calculated at constant value, so that inflation factors have been allowed for. It is also of interest to compare the Output at Sales Value for the two technologies of PWBs and Thick film + Thin film circuits as a \% of the total interconnection business in the UK. This is done in Figure 5, and it can be seen that as well as a continued grow th in the business, the \% associated with PWBs appears to be falling and the \% associated with film circuits is rising.

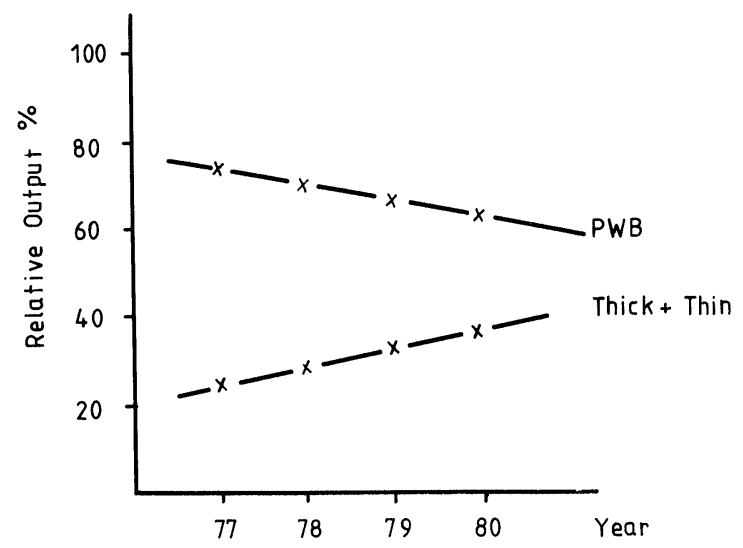

FIGURE 5 Relative \% of to tal interconnection Output at Sales Value occupied by the two technologies, PWBs., and film circuits (After Ref. 10)

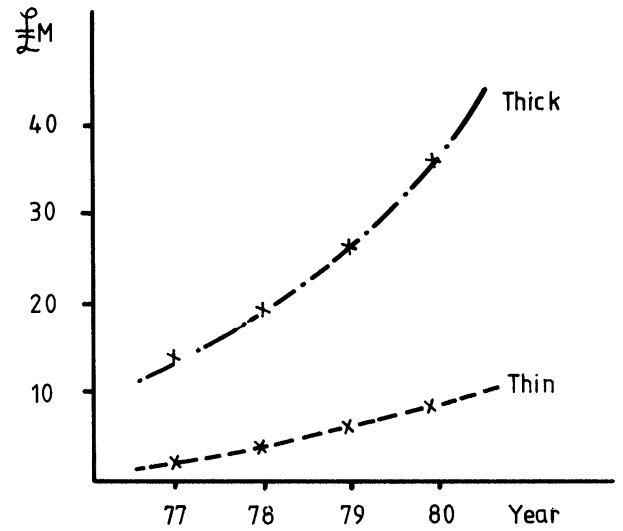

FIGURE 6 Output at Sales Value in the UK of thick and thin film circuits separately (After Ref. 10)

The Output at Sales Value of the two film interconnection systems has been analysed from the Working Party data. ${ }^{10}$ Figure 6 shows this data, where it can be seen that Thin film circuits account for approximately $1 / 5$ of the total output in this sector.

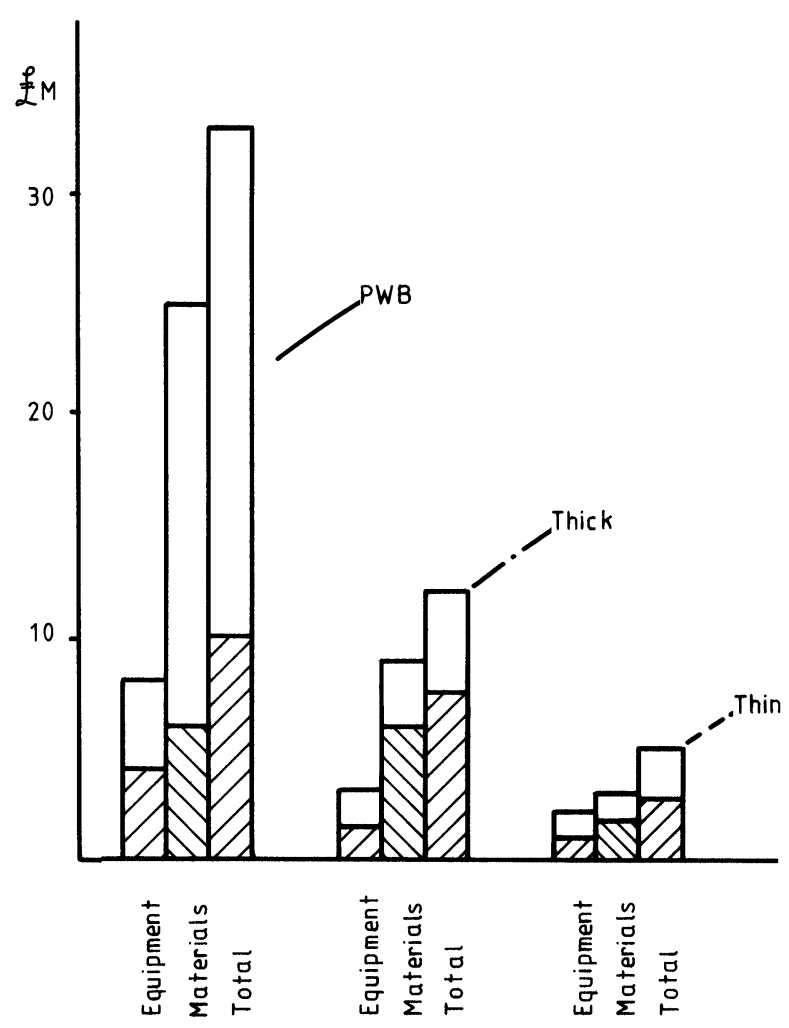

FIGURE 7 Expected annual spend in the UK in 1980 for Equipment and Materials in the three interconnection technologies. (Imports shown as hatched areas.) (After Ref. 10) 
TABLE VII

U.K. Output at sales value and total market usage for interconnection products ( $£ \mathrm{M})$ (after Ref.10.)

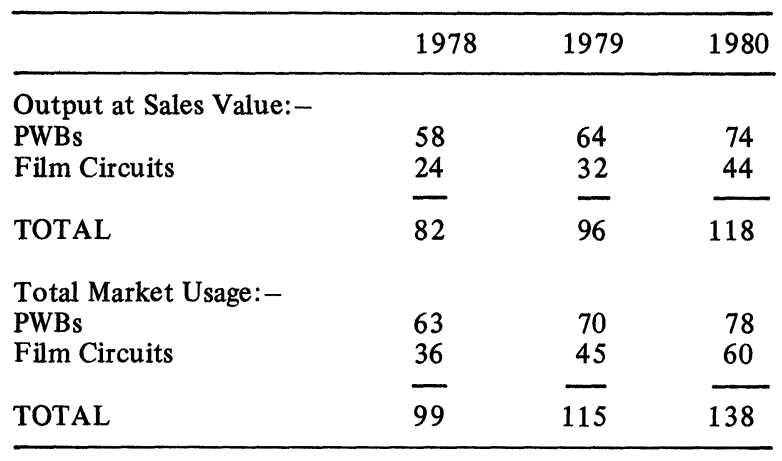

A considerable amount of data was collected and analysed by the Working Party giving the value and the sources of equipment and materials bought by UK manufacturers. ${ }^{10}$ Figure 7 summarizes this data, both in terms of the three interconnection technologies and also in terms of the UK reliance on equipment and materials from outside of the country. Details are given in the Appendix.

\subsection{Summary}

Table VII summarizes the UK Output at Sales Value and the Total Market Usage for interconnection technology, as derived by the Working Party. ${ }^{10} \mathrm{It}$ should be noted that the 1979 Output at Sales Value for permanent interconnection products at $£ 96 \mathrm{M}$ compares with the inflation corrected figure of $£ 105 \mathrm{M}$ for the UK Output at Sales Value for integrated circuits, derived from the data given by Mackintosh. ${ }^{7}$

\section{RESEARCH AND DEVELOPMENT}

\subsection{Introduction}

It was felt by the Working Party that it was of considerable interest to establish a concensus of opinion on the $\mathrm{R} \& \mathrm{D}$ projects that should be followed in the immediate and longer term future in order to maintain and increase the viability of interconnection technology in the UK. Such a study did not lead to a detailed review of present activity and, therefore, this paper does not attempt to examine existing programmes in the field. A list of discussion topics was drafted and examined with respondents, either directly or by correspondence, to obtain a concensus of opinion. Such discussion topics did not attempt to limit the areas under examination - Printed Wiring, Thick film and Thin film systems were all considered, and thus all methods of deposition and preparation were of interest. ${ }^{1,2,11}$ It was felt by the Working Party that this was an important aspect of their analysis, since a narrow confinement of the study to only one interconnection technique would have given a biased view of the problems that needed to be solved.

The discussion topics were structured into four main groups, and Table VIII summarizes these.

\subsection{Immediate Projects}

It is not possible in the space available to detail all the considerations that lead from the discussion areas to the recommendations that the Working Party made with regard to immediate projects. However, the results of these considerations are given in Table IX there are 29 project requirements in all. These projects, although classified as 'immediate', relate to time scales of between 1 and 5 years. Problems involving shorter periods were felt to be of such pressing importance as to be already under consideration by industry.

It is a difficult task to derive an order of priority for the projects listed in Table IX. It can argued that all the projects concerned with PWB development should take low priority on the grounds that such products have been around for many years and, therefore, there is little hope of any major advances in the field at this time. Also it has been pointed out $^{12}$ that the cost per unit area of a ceramic film circuit is about the same as that of a 4-layer PWB, but that the interconnection density can be ten times higher. Hence very substantial benefits in size and weight of the assemblies, and in economic terms as well, can result from transferring from the interconnection technologies of the multilayer PWB to some form of hybrid system. Furthermore it has been suggested that the fragmented nature of the PWB industry does not make this sector readily capable of undertaking major R \& D work or taking widespread advantage of research outputs, with 'too many of the companies being too small and undercapitalized'. ${ }^{13}$ However, such strictures are not true for all companies involved in PWB production. Improved PWB systems will be required if only to match the large number of pins per device and the line widths that will be required by the improvements to integrated circuit devices that will take place, ${ }^{14}$ and there are firms capable of this work. 
TABLE VIII

Discussion areas used to give an analysis of immediate R \& D requirements in interconnection technology (after Ref.10.)

\begin{tabular}{|c|c|c|}
\hline Area & Sub-area & Detailed interest \\
\hline Deposited Components & $\begin{array}{l}\text { Printed Wiring } \\
\text { Thick film } \\
\text { Thin film }\end{array}$ & $\begin{array}{l}\text { Conductive elements } \\
\text { Resistive elements } \\
\text { Conductors \& Resistors } \\
\text { Dielectrics }\end{array}$ \\
\hline Substrates & $\begin{array}{l}\text { Printed Wiring } \\
\text { Thick film } \\
\text { Thin film }\end{array}$ & $\begin{array}{l}\text { Standard substrates } \\
\text { Non-standard substrates }\end{array}$ \\
\hline Added Components & $\begin{array}{l}\text { Passive Components - } \\
\text { without leads } \\
\text { Components - with leads } \\
\text { Passive Components - } \\
\text { - attachment to Thick } \\
\text { film circuits } \\
\text { Microwave hybrid circuits }\end{array}$ & $\begin{array}{l}\text { Procurement \& transport } \\
\text { Attachment methods } \\
\text { Removal/replacement } \\
\text { Testing after assembly } \\
\text { Reliability in hybrid } \\
\text { circuits } \\
\text { Problems of large area } \\
\text { chips }\end{array}$ \\
\hline Packaging & $\begin{array}{l}\text { Hermetic } \\
\text { Plastic } \\
\text { Design Concepts } \\
\text { Attachment of Packaged modules }\end{array}$ & \\
\hline
\end{tabular}

Arguments can also be advanced against expenditure on resistive thin film problems. Low TCR films were investigated in the 1960s, e.g. Ref. 15, and little improvement can be expected now. Nevertheless, realization of the potential of such components is now with us, and due to the better understanding of the nature of the conducting processes in thin metal layers, advances are being made in this area of technology.

The Working Party also felt that the establishment of a priority list of projects implied that some of the projects were of a second class nature. As no such implications are wished, no priorities have been assigned to the list in Table IX.

\subsection{Longer Term Projects}

For longer time scale problems, it is recognized that microminiaturization will be a major driving force in the progress of interconnection technology. This will involve the scaling down of sizes of the interconnections. The increased use of VLSI, particularly with regard to the further development of large scale computers, will demand interconnection technologies that will have sub-micron line definition compatible with the connections to the chips themselves, and with the criteria of reduced interconnection lead length so as not to limit operational speed at low power.

Some of the specific areas that need investigation have been highlighted by an NRC report recently published $^{16}$ and considered by the Working Party. Six areas were suggested as being of special interest and these are:

a) Inorganic resists such as As-S and Ge-Se that do not have to be removed, as with present systems, because of temperature limitations imposed by subsequent device or substrate processing. 
TABLE IX

Immediate $\mathrm{R} \& \mathrm{D}$ project recommendations in interconnection technology (after Ref.10.)

Activity

Deposited Components

Substrates

Added Components

Packaging
Investigation recommendations

Low temperature electroless $\mathrm{Cu}$ for PWBs - with particular reference to understanding adhesion of such deposits.

Improvement to finish of $\mathrm{Cu}$ foils - for the semi-additive processes thinner foils have definite process and economic advantages but suffer from poor finish and porosity.

Translation of software for N.C. PWB systems - from one system to another.

Economics of different PWB processes - i.e. a full cost analysis of the economics of subtractive, semi-additive, additive and photoplating technology.

Base metal conducting and resistive systems - to give low cost conductors and low cost general purpose resistors.

Improvements in dielectric materials - both in yield and performance.

High stability resistive films - (TCR $<25 \mathrm{ppm} / \mathrm{deg}$. C.).

Accelerated life testing of resistors - particularly with regard to a method of relating accelerated life tests to long term stability.

Reduction of line width in resistors - down to $1 \mu \mathrm{m}$ or less.

Dimensionally highly stable PWBs - using fine weave glass cloths and/or improved resins.

Low dielectric loss substrates - for use for strip lines and microwave applications. Investigation of different substrates including multilayer systems, plasma sprayed metals (e.g. $\mathrm{Al}_{2} \mathrm{O}_{3}$ ) and low alkalie ceramics.

Epoxy mounting of devices - the use of organic adhesives that have a long shelf life, are only one-part and have a low curing temperature.

Printed circuit boards for beam leads and tape bonded semi conductors suitable PWB metallizations required.

Chip replacement systems - including use of eutectics. Removability is essential for the more expensive circuits.

Reliability assessment of semi conductor chips after mounting.

Attachment problems of large chips - including heating effects (thermal managment).

Automatic semi conductor chip placement systems.

Low stress passive component mounting systems - that minimize bond and performance degradation due to expansion mismatch stresses during temperature cycling.

Failure of ceramic capacitors at low voltages

Low cost printable conducting adhesives - use of non precious metals.

Sealing of ceramic encapsulation systems.

Welding techniques for encapsulation - epoxy resin systems are thought of as not being good enough for high reliability applications.

Determination of testing standards - e.g. criteria for water vapour measurement in packages at a sufficiently sensitive level as to be appropriate for a package life of 10 years or more.

Degradation effects of mechanical stresses developed by plastic encapsulation (particularly if components subsequently are cycled to $-10^{\circ} \mathrm{C}$ or less).

Chemical effect of organic encapsulants of reliability of components.

The use of soft materials can reduce mechanical stress whilst at the same time still giving chemical protection.

Methods of attachment of rigid multi-lead packages - in order to increase the packing density. 
b) High definition lithography that will be capable of sub-micron definition - such techniques include those of X-ray, Electron beam, and Plasma etching.

c) Improved interconnection systems based on conventional techniques but using alternative materials such as silicides.

d) New interconnection materials such as polymerics - these are conductors but do not contain metallic atoms - e.g. polythiazyl, $(\mathrm{SN})_{x}$; polyacetylene, $(\mathrm{CH})_{x}$. Also anisotropic conductors such as graphite intercalation compounds are of interest.

e) Further investigation of the problems and limitations imposed by electromigration.

f) Improved ultra thin insulators.

\section{DISCUSSION AND CONCLUSIONS}

\subsection{Market Data}

The data obtained from the Working Party questionnaire has been correlated with a wide variety of published market information. The figures for the three areas of permanent interconnection technology have been found to be in reasonable agreement with the published data and has shown the economic importance of interconnection systems. The conclusions from this study have been summarized in Table VII.

\subsection{Permanent Interconnection Technology and Microelectronics}

A widespread misconception is that 'microelectronics' is only 'silicon chips'. This is not so - in fact microelectronics is clearly defined in BS $9400 / 9450$ as 'The concept of the construction and use of highly miniaturized electronic circuits'. PWBs and Thick and Thin film technologies are a vital and integral part of microelectronics. The viability of the total microelectronic circuit business is related to the need to interconnect the circuits or devices and it is thus no use developing sophisticated integrated circuit systems if the technology is not available to interconnect these systems in a manner that is effective in terms of system performance, reliability, size and cost. Such considerations apply equally well to the use of components other than chips, and the Working Party saw clear examples in surface acoustic wave devices, microwave systems including integrated optics, Hall effect switches and sensors, memory systems including low temperature devices and bubble memories, implantation medical electronics and displays.

\subsection{Semiconductor Technology}

With reference to the semiconductor microelectronic market, it is possible to divide the present and future activity into two areas.

1) The use of high density systems such as VLSI and Josephson technology. ${ }^{17}$ The essence of this approach is to provide a large, high speed, digital computing system at low cost. In order not to lose the speed inherent in the chip design itself it is vital for the interconnection system to the high density devices to be designed by the device manufacturer as part of the system itself.

2) The use of LSI and Discrete devices. In this area chip manufacturers are interested in making standard products that will be used by the system designer as he wishes. Such an approach will waste space over that involved in 1), if only because of the packaging that the chip manufacturer will use to protect his circuits. The use of a standard chip will also imply redundancy in the chip design and application. If the market is large enough, however, the chip manufacturer will still be interested in mounting his chips in his own total sub systems, and selling these. (e.g. Texas and hand calculators.)

Even the use of chips by a separate system designer is subject to change. It can be argued that as the LSI chips become more complex, fewer and fewer of them will be required and hence added value in making up whole circuits will be reduced. In these circumstances, either the chip manufacturer will be forced to make the whole function, or he will not sell his chips, or conversely, the circuit manufacturer will have to make the required chips himself. If this trend is coupled with that of the considerable amount of research that is going into the problem of yield improvement in chip manufacture, and the effect that this will have on the economic manufacture of only small numbers of chips - down to 5 per design is being quoted - then it is possible to predict that the open market hybrid business as a separate entity will get relatively smaller, but the total need for interconnection technology will increase rapidly within the context of the system house of chip manufacturer's own business. However, it must be emphasized that the widening application of electronics in the coming years will lead to large increases in the total interconnection business including both open and in house manufacture. The effect in the UK depends on the nature of investment in this country. For full involvement in the high density systems, it can be argued that this could only be done effectively in 
terms of a European (EEC) based approach, that would enable us in Europe to compete with the investment being made in the US or Japan. The use of LSI and Discrete devices is the other approach, and such a development has been implied by the NEDC Electronic Components Sector Working Party report. ${ }^{18}$ This document identifies the need for volume production of selected multi-application semiconductor circuits, and notes that this can be done in one of three ways:

1) Investment by an existing company.

2) A joint venture between a UK based company and one from overseas.

3) A UK owned company (e.g. INMOS).

All these possibilities, and particularly those of 1) and 3), would imply a considerable activity on the part of the interconnection circuit manufacturer as distinct from the chip manufacturer, in making complete systems. Research in the UK should, therefore, be directed towards improving interconnection technology as a separate business.

\section{SUMMARY}

This Paper had been concerned with the permanent interconnection of electronic components into sub systems. A marketing survey has been given that has included new data obtained by an Electronics Research Committee Working Party on Permanent Interconnection Technology, and the economic importance of the technology has been clearly demonstrated.

Research work needed in the field has been discussed in terms of immediate and long term time scales, and the problem areas that need investigating have been itemized.

The following major conclusions have been reached:

1) The economic importance of Permanent Interconnection Technology has been demonstrated. The output at sales value in the UK of interconnection technology products is very nearly as great as the output at sales value of integrated circuits in the UK. Within permanent interconnection technology $2 / 3$ rd of the output at sales value is associated with PWBs and $1 / 3$ rd with thick/thin film circuits.

2) 29 Immediate time scale $R \& D$ problems have been recognized covering all three interconnection technologies.
3) Longer time scale $R$ \& D problems will be associated with the continuing decrease in size of addon electronic components.

4) Solutions to the interconnection technology problems in the longer term cannot be obtained within an environment in which the three permanent interconnection technologies are separated from each other either economically or scientifically.

5) It is suggested that the open market interconnection technology business as a separate entity will increase as time progresses. However, the total need for interconnection technology will increase even more rapidly within the context of the system house or chip manufacturers own business.

\section{ACKNOWLEDGEMENTS}

The authors of this Paper were Members of the ERC Working Party on Permanent Interconnection Technology.

The Working Party Report ${ }^{10}$ and, therefore, this Paper is due to the dedicated efforts of the Working Party, which included:

$\begin{array}{ll}\text { Chairman } & \text { Prof. D. S. Campbell, Loughborough } \\ & \text { University of Technology } \\ \text { Vice-Chairman } & \text { Prof. P. L. Kirby, Welwyn Electric Ltd. } \\ \text { Secretary } & \text { Mr. A. N. Pearse, RSRE } \\ \text { Members } & \text { Mr. D. Boswell, ITT Components Group } \\ & \text { Dr. H. T. Law, Ferranti/Edinburgh } \\ & \text { University } \\ & \text { Mr. W. MacLeod-Ross, Plessey/Precision } \\ & \text { Circuits (Anglia) Ltd. }\end{array}$

The Working Party is deeply grateful to all those members of the scientific community who discussed and/or corresponded so readily with us, and without whom no data collection or consensus of opinions would have been possible.

Naturally, in any reporting of this nature, there is an inevitable bias due to the views of the authors who must be held responsible for the contents of this paper.

\section{REFERENCES}

1. P. Lund, Generation of Precision artwork for Printed Circuit Boards, Wiley, Chichester, UK, 1979.

2. C. A. Harper, Handbook of Thick Film Hybrid Microelectronics, McGraw-Hill, NY, 1974.

3. L. I. Maissel and R. Glang, Handbook of Thin Film Technology, McGraw-Hill, NY, 1971.

4. D. J. Hamilton and W. G. Howard, Basic Integrated Circuit Engineering, pp. 514-53, McGraw-Hill, NY, 1975.

5. C. Young, The New Penguin Dictionary of Electronics, Penguin Books, London, p. 242, 1979.

6. Electronics, 52, pp. 105-28, January 1979.

7. Mackintosh Year Book, Mackintosh Publications, Luton, UK, 1979.

8. P. Evison, International Management Report, "Electronics, The Market to 1982", Financial Times, London, 1978. 
9. Electronics, 53, pp. 125-48, January 1980.

10. Report of the Working Party on Permanent Interconnection Technology, ERC Document No. 2715, January 1980. (Presented to Council, March 1980.)

11. D. S. Campbell, "Preparation methods for Thin-film devices", Active and Passive Thin Film Devices, Ed. T. J. Coutts, Academic Press, London, pp. 23-55, 1979.

12. C. T. Goddard, Proc. 29 Electronic Components Conference, "The Role of Hybrids in LSI Systems", pp. 80-4, 1979.

13. Larsen-Sweeney Ass. Ltd., Report No. 417, "Printed Circuits in the UK".
14. C. L. Lassen, Electronics, 53, pp. 113-21, September 1979.

15. D. S. Campbell and B. Hendry, "The Effect of Composition on the Temperature Coefficient of Resistance of NiCr Films", Brit. J. Appl. Phys., 16, pp. 1719-25, 1965.

16. "Thin Film Microstructure Science and Technology", Report of the National Research Council, National Academy of Science, Washington D.C., USA, 1979.

18. NEDC Electronics Components Sector Working Party Report Ref., ISBN 072920288 7, 1979.

\section{Appendix}

\section{MATERIALS AND EQUIPMENT DATA FOR PWBs, THICK FILM AND THIN FILM CIRCUITS}

TABLE A.1.

PWB material data

\begin{tabular}{|c|c|c|c|c|c|c|c|c|c|}
\hline & \multicolumn{5}{|c|}{ Expenditure (Kf) } & \multicolumn{4}{|c|}{$\begin{array}{l}\text { Total Expenditure in terms of } \\
\text { Country of Origin }(\mathrm{K} f)\end{array}$} \\
\hline & 1977 & 1978 & 1979 & 1980 & Total & 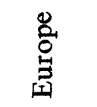 & 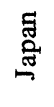 & 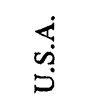 & : \\
\hline \multicolumn{10}{|l|}{ Laminate } \\
\hline a) Copper Clad & 1495 & 1557 & 1608 & 1683 & 6343 & 1388 & - & 8 & 4947 \\
\hline b) Paper Phenolic & 598 & 598 & 649 & 662 & 2507 & 170 & - & - & 2337 \\
\hline c) Glass Epoxide & 480 & 480 & 555 & 567 & 2082 & 304 & - & 8 & 1770 \\
\hline d) Glass Polyester & 68 & 80 & 80 & 80 & 308 & - & - & - & - \\
\hline e) Glass PTFE ${ }^{\text {b }}$ & 5 & 15 & 15 & 15 & 50 & 8 & - & 42 & 24 \\
\hline f) Flexible Polyimide ${ }^{b}$ & 80 & 80 & 80 & 93 & 333 & - & - & 309 & 24 \\
\hline g) Rigid Polyimide & - & 5 & 5 & 5 & 15 & - & - & 15 & - \\
\hline Drills/cuttersa & 129 & 179 & 212 & 344 & 864 & 60 & - & 684 & 120 \\
\hline \multicolumn{10}{|l|}{ Plating Solutions } \\
\hline a) Electroless $\mathrm{Cu}$. & 84 & 131 & 164 & 252 & 631 & - & - & - & 595 \\
\hline b) Copper & 51 & 61 & 74 & 105 & 291 & - & - & - & 291 \\
\hline c) $\mathrm{Tin} / \mathrm{lead}$ & 38 & 48 & 61 & 92 & 239 & - & - & - & 239 \\
\hline d) $\mathrm{Tin}$ & 5 & 5 & 5 & 5 & 20 & - & - & - & 20 \\
\hline e) Gold & 488 & 613 & 633 & 746 & 2480 & - & - & 189 & 2291 \\
\hline f) Nickel & 5 & 5 & 5 & 10 & 25 & - & - & - & 25 \\
\hline Dry Film Photo Resists ${ }^{b}$ & 198 & 304 & 361 & 412 & 1275 & 802 & - & 473 & - \\
\hline Screen Printed Resists & 66 & 99 & 99 & 99 & 363 & - & - & 53 & 310 \\
\hline Stencil Materials & 53 & 53 & 92 & 92 & 290 & 142 & - & - & 148 \\
\hline Etching sol's & 92 & 105 & 151 & 151 & 499 & 121 & - & 72 & 306 \\
\hline Sensitisers and Conditioners & 10 & 15 & 28 & 28 & 81 & - & - & - & 81 \\
\hline Fusing Fluids/Fluxes ${ }^{a}$ & 40 & 40 & 53 & 53 & 186 & - & - & 126 & 60 \\
\hline Solder Alloys & 30 & 30 & 69 & 69 & 198 & - & - & 20 & 178 \\
\hline Coding/Marking Inks & 30 & 30 & 30 & 43 & 133 & - & - & - & 133 \\
\hline \multicolumn{10}{|l|}{ Solder Masks } \\
\hline a) Liquid & 40 & 40 & 40 & 66 & 186 & - & - & - & 186 \\
\hline b) Dry Film & 5 & 18 & 28 & 79 & 130 & - & - & 51 & 79 \\
\hline Tools, Jigs & 151 & 208 & 258 & 408 & 1025 & 95 & - & 223 & 707 \\
\hline \multirow[t]{2}{*}{ TOTALS } & 4241 & 4799 & 5355 & 6159 & 20554 & 3090 & - & 2309 & 15155 \\
\hline & \multicolumn{5}{|c|}{ Percentage of total expenditure } & 15.0 & 0 & 11.2 & 73.8 \\
\hline
\end{tabular}

aItems for which import level is $>66 \%$ of total usage

bItems for which import level is $>90 \%$ of total usage 
TABLE A. 2.

PWB equipment data

\begin{tabular}{|c|c|c|c|c|c|c|c|c|c|}
\hline & \multicolumn{5}{|c|}{ Expenditure $(\mathrm{K} f)$} & \multicolumn{4}{|c|}{$\begin{array}{l}\text { Total Expenditure in terms of } \\
\text { Country of Origin }\end{array}$} \\
\hline & 1977 & 1978 & 1979 & 1980 & Total & 这 & 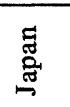 & $\begin{array}{l}\overleftarrow{\omega} \\
\dot{\omega}\end{array}$ & $\stackrel{u}{a}$ \\
\hline CAD equipment & 75 & 116 & 173 & 209 & 573 & - & - & 150 & 423 \\
\hline Artwork generators & 36 & - & - & 90 & 126 & - & - & 18 & 108 \\
\hline Cameras \& Accessories & 20 & 25 & 105 & 100 & 250 & 76 & 82 & - & 92 \\
\hline Air condition plant & 84 & 95 & 76 & 113 & 368 & 14 & 23 & - & 239 \\
\hline Cutting equipment & 5 & 28 & 87 & 111 & 231 & 54 & - & 74 & 103 \\
\hline Drills ${ }^{b}$ & 336 & 222 & 540 & 285 & 1383 & 202 & - & 1082 & 99 \\
\hline Deburring \& clean & 56 & 105 & 66 & 128 & 355 & 116 & - & 45 & 194 \\
\hline Electroless plating & 46 & 105 & 289 & 51 & 491 & - & - & - & 491 \\
\hline Photo imaging & 69 & 123 & 128 & 82 & 402 & 166 & - & 79 & 157 \\
\hline Screen printing & 82 & 123 & 92 & 87 & 384 & 191 & - & - & 192 \\
\hline Electroplating & 51 & 69 & 377 & 59 & 556 & - & - & - & 556 \\
\hline Resist strip & 15 & 56 & 100 & 33 & 204 & 42 & - & 32 & 130 \\
\hline Etching & 72 & 74 & 113 & 112 & 371 & 124 & - & 110 & 137 \\
\hline Tin lead fusinga & 10 & 51 & 51 & 54 & 166 & - & - & 133 & 33 \\
\hline Coding $b$ & - & 18 & 36 & 5 & 59 & - & - & 59 & - \\
\hline Screen print solder mask & 23 & 28 & - & 41 & 92 & 59 & - & - & 33 \\
\hline Dry film solder mask ${ }^{\mathrm{a}}$ & 18 & 28 & 41 & 90 & 177 & 54 & - & 123 & - \\
\hline Roller Solder coat & 5 & 15 & 10 & 10 & 40 & - & - & - & 40 \\
\hline Profiling & 46 & 191 & 173 & 80 & 490 & 2 & - & 311 & 177 \\
\hline Ovens & 25 & 56 & 48 & 30 & 159 & - & - & - & 159 \\
\hline Multilayer laminate store & 10 & 5 & 28 & 10 & 53 & - & - & - & 53 \\
\hline Press & 36 & 54 & 5 & 59 & 154 & - & - & 93 & 61 \\
\hline Multilayer etch back & - & 23 & 41 & 10 & 74 & - & - & - & 74 \\
\hline Flex coverlay & 5 & 5 & 5 & 5 & 20 & - & - & 41 & - \\
\hline Microscopes & 20 & 10 & 15 & 20 & 65 & 20 & 20 & - & 25 \\
\hline NDT thickness & 20 & 15 & 25 & 20 & 80 & 10 & - & 35 & 35 \\
\hline Autotest & 5 & 51 & 121 & 54 & 231 & 16 & - & 36 & 179 \\
\hline \multirow[t]{2}{*}{ TOTALS } & 1170 & 1691 & 2781 & 1953 & 7595 & 1146 & 125 & 2513 & 3801 \\
\hline & \multicolumn{5}{|c|}{ Percentage of total expenditure } & 15.1 & 1.6 & 33.1 & 50.2 \\
\hline
\end{tabular}

altems for which import level is $>66 \%$ of total usage

bItems for which import level is $>90 \%$ of total usage 
TABLE A.3.

Thick film materials data

\begin{tabular}{|c|c|c|c|c|c|c|c|c|c|}
\hline & \multicolumn{5}{|c|}{ Expenditure $(\mathrm{K} £)$} & \multicolumn{4}{|c|}{$\begin{array}{l}\text { Total Expenditure in terms of } \\
\text { Country of Origin }(K £)\end{array}$} \\
\hline & 1977 & 1978 & 1979 & 1980 & Total & 芯 & $\begin{array}{l}\text { 芯 } \\
\text { 芯 }\end{array}$ & $\begin{array}{l}\dot{\longleftrightarrow} \\
\dot{\omega} \\
\dot{\rho}\end{array}$ & $\stackrel{4}{\square}$ \\
\hline Artwork Mats. & 30 & 48 & 58 & 71 & 207 & 15 & 5 & 56 & 131 \\
\hline Substrates & 356 & 586 & 856 & 1155 & 2953 & 198 & 118 & 1098 & 1539 \\
\hline Cermet inks & 551 & 669 & 919 & 1594 & 3733 & - & - & 2268 & 1465 \\
\hline Beam lead Chip semi's ${ }^{a}$ & 203 & 277 & 408 & 550 & 1438 & 50 & - & 998 & 390 \\
\hline Encap. semi's & 206 & 206 & 228 & 276 & 916 & 461 & 33 & 109 & 313 \\
\hline Chip caps ${ }^{a}$ & 250 & 268 & 362 & 357 & 1237 & 51 & 111 & 826 & 249 \\
\hline Encap. Caps. & 62 & 67 & 67 & 67 & 263 & 25 & - & 35 & 203 \\
\hline Wiresa & 45 & 51 & 39 & 41 & 176 & 22 & - & 117 & 37 \\
\hline Solders & 79 & 85 & 85 & 136 & 385 & - & - & 84 & 301 \\
\hline Packages $b$ & 309 & 493 & 631 & 831 & 2264 & 454 & 75 & 1689 & 46 \\
\hline Resins \& Polymers a & 43 & 87 & 85 & 111 & 326 & 15 & 5 & 232 & 74 \\
\hline Others $^{a}$ & 80 & 116 & 210 & 210 & 616 & 450 & - & - & 166 \\
\hline \multirow[t]{2}{*}{ Totals } & 2214 & 2953 & 3948 & 5399 & 14514 & 1741 & 347 & 7512 & 4914 \\
\hline & \multicolumn{5}{|c|}{ Percentage of total expenditure } & 12.0 & 2.4 & 51.7 & 33.9 \\
\hline
\end{tabular}

a Items for which import level is $>66 \%$ of total usage

bItems for which import level is $>90 \%$ of total usage

Negligible quantities of add-on resistors were reported.

TABLE A.4

Thick film equipment data

\begin{tabular}{|c|c|c|c|c|c|c|c|c|c|}
\hline & \multicolumn{5}{|c|}{ Expenditure $(\mathrm{K} f)$} & \multicolumn{4}{|c|}{$\begin{array}{l}\text { Total Expenditure in terms of } \\
\text { Country of Origin }(\mathrm{K} £)\end{array}$} \\
\hline & 1977 & 1978 & 1979 & 1980 & Total & 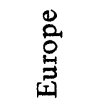 & 芯 & $\begin{array}{l}\dot{\leftrightarrow} \\
\dot{\infty}\end{array}$ & $\stackrel{ن}{\dot{m}}$ \\
\hline Clean Rooms & 169 & 210 & 265 & 96 & 740 & - & - & 3 & 737 \\
\hline Artwork aids & 37 & 14 & 11 & 24 & 86 & - & - & 37 & - \\
\hline Substrate Cleaners & 5 & 53 & 54 & 52 & 164 & - & - & 20 & 144 \\
\hline Screen printers & 82 & 86 & 111 & 150 & 429 & - & - & 158 & 271 \\
\hline Furnaces ${ }^{a}$ & 74 & 121 & 166 & 139 & 500 & 32 & - & 302 & 166 \\
\hline Resistor trim ${ }^{a}$ & 129 & 367 & 276 & 245 & 1017 & 20 & - & 813 & 184 \\
\hline Scribe $^{a}$ & 62 & 57 & 52 & 55 & 226 & 73 & - & 142 & 11 \\
\hline Comp. attach ${ }^{a}$ & 31 & 66 & 158 & 109 & 364 & 18 & 10 & 274 & 62 \\
\hline Wire bonders $b$ & 80 & 90 & 142 & 96 & 408 & - & - & 400 & 8 \\
\hline Probers $^{\mathrm{a}}$ & 21 & 37 & 55 & 51 & 164 & - & - & 120 & 44 \\
\hline Circuit adjust & 43 & 103 & 49 & 103 & 298 & - & - & 196 & 102 \\
\hline Funct'1 test eq. a & 115 & 308 & 286 & 214 & 923 & 11 & - & 603 & 309 \\
\hline Q.C. eq. & 38 & 58 & 98 & 123 & 317 & 24 & 10 & 149 & 134 \\
\hline Encaps. & 119 & 96 & 103 & 173 & 491 & 12 & - & 181 & 298 \\
\hline Leak det. & 56 & 28 & 20 & 15 & 119 & - & - & 41 & 78 \\
\hline Marking & 33 & 28 & 50 & 40 & 151 & - & 10 & 70 & 71 \\
\hline Others & 25 & 266 & 209 & 265 & 765 & 33 & - & 147 & 585 \\
\hline \multirow[t]{2}{*}{ TOTALS } & 1119 & 1988 & 2105 & 1950 & 7162 & 223 & 30 & 3656 & 3253 \\
\hline & \multicolumn{5}{|c|}{ Percentage of total expenditure } & 3.1 & 0.4 & 51.1 & 45.4 \\
\hline
\end{tabular}

aItems for which import level is $>66 \%$ of total usage

bItems for which import level is $>90 \%$ of total usage 
TABLE A.5.

Thin film materials data

\begin{tabular}{|c|c|c|c|c|c|c|c|c|c|}
\hline & \multicolumn{5}{|c|}{ Expenditure $(\mathrm{K} \mathfrak{f})$} & \multicolumn{4}{|c|}{$\begin{array}{l}\text { Total Expenditure in terms of } \\
\text { Country of Origin }(\mathrm{K} £)\end{array}$} \\
\hline & 1977 & 1978 & 1979 & 1980 & Total & 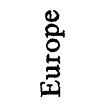 & 节 & $\begin{array}{l}\dot{4} \\
\dot{\varphi} \\
\dot{D}\end{array}$ & $\stackrel{\dot{\Delta}}{\dot{b}}$ \\
\hline Artwork Materials & 11 & 11 & 11 & 16 & 49 & - & - & 25 & 24 \\
\hline Substrates $b$ & 33 & 53 & 53 & 66 & 205 & - & - & 205 & - \\
\hline Evap'n. sources & 11 & 24 & 29 & 28 & 92 & - & - & - & 92 \\
\hline Pre-coated substrates $c$ & 98 & 98 & 118 & 168 & 482 & 449 & - & 33 & - \\
\hline Photoresist and developers $\mathrm{C}$ & 21 & 21 & 21 & 25 & 88 & 20 & - & 68 & - \\
\hline Chemical etchants & 20 & 15 & 15 & 15 & 65 & - & - & - & 65 \\
\hline Photomask Plates & 11 & 11 & 11 & 15 & 48 & - & - & 20 & 28 \\
\hline Chip semiconductors & 61 & 168 & 368 & 468 & 1065 & - & - & 780 & 285 \\
\hline Chip capsa & 38 & 51 & 84 & 141 & 314 & 133 & - & 126 & 55 \\
\hline Other discrete applique devices & 48 & 61 & 74 & 94 & 277 & - & - & 138 & 139 \\
\hline Bonding wirec & 15 & 28 & 28 & 48 & 119 & - & - & 119 & - \\
\hline Epoxy & 16 & 16 & 16 & 29 & 77 & - & - & 39 & 38 \\
\hline Solder Preforms $\mathrm{s}^{\mathrm{a}}$ & 10 & 23 & 23 & 43 & 99 & - & - & 79 & 20 \\
\hline Solder wire & 6 & 6 & 6 & 6 & 24 & - & - & 4 & 20 \\
\hline Sub-carriers for s/c dicea & 10 & 23 & 43 & 85 & 161 & - & - & 141 & 20 \\
\hline Packages $b$ & 103 & 198 & 248 & 373 & 922 & - & - & 856 & 66 \\
\hline Cleaning Solvents & 38 & 38 & 38 & 58 & 172 & 20 & - & - & 152 \\
\hline Wire bond toolsa & 15 & 28 & 28 & 48 & 119 & - & - & 99 & 20 \\
\hline Expendable hand tools & 21 & 21 & 21 & 21 & 84 & 28 & - & 8 & 48 \\
\hline Other tools $b$ & 11 & 11 & 24 & 24 & 70 & - & - & 66 & 4 \\
\hline TOTALS $\dagger$ & 597 & 905 & 1259 & 1771 & 4532 & 650 & - & 2806 & 1076 \\
\hline \multirow[t]{2}{*}{ Corrected TOTALS } & 398 & 604 & 840 & 1181 & 3023 & 434 & - & 1872 & 718 \\
\hline & \multicolumn{5}{|c|}{ Percentage of total expenditure } & 15.1 & & 59.3 & 25.6 \\
\hline
\end{tabular}

aItems for which import level is $>66 \%$ of total usage

bItems for which import level is $>90 \%$ of total usage

cItems for which import level is $100 \%$ of total usage

Due to the lack of sensitivity of the Working Party's questionnaire in the range $1 \mathrm{~K}-10 \mathrm{~K} f$ the small number of replies received and the preponderance of replies in the $1 \mathrm{~K}-10 \mathrm{~K} £$ range, the total material expenditures will appear high. The experience of the Working Party has lead to the correcting of these figures by applying a multiplication factor of $2 / 3$ to the totals and these corrected figures have been used in the presentation (e.g. Table VII. Figure 7) 
TABLE A.6.

Thin film equipment data

\begin{tabular}{|c|c|c|c|c|c|c|c|c|c|}
\hline & \multicolumn{5}{|c|}{ Expenditure $(\mathrm{K} £)$} & \multicolumn{4}{|c|}{$\begin{array}{l}\text { Total Expenditure in terms of } \\
\text { Country of Origin }(\mathrm{K} £)\end{array}$} \\
\hline & 1977 & 1978 & 1979 & 1980 & Total & 䓃 & 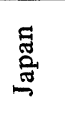 & $\begin{array}{l}\dot{\leftrightarrow} \\
\dot{\rho} \\
\dot{\rho}\end{array}$ & $\stackrel{\dot{v}}{\dot{D}}$ \\
\hline Installation clean rooms & 211 & 47 & 161 & 119 & 538 & - & - & 5 & 533 \\
\hline Artwork materials & 11 & 11 & 11 & 11 & 44 & - & - & 20 & 24 \\
\hline Layout aids & 24 & 6 & 11 & 11 & 52 & - & - & 10 & 42 \\
\hline Photo red'n cameras & 11 & 6 & 23 & 19 & 59 & - & - & - & 59 \\
\hline Cleaning systems & 48 & 28 & 23 & 46 & 145 & - & - & 94 & 51 \\
\hline Driers and ovens & 20 & 10 & 28 & 38 & 96 & - & - & - & 96 \\
\hline Loaders & 10 & 10 & 10 & 28 & 58 & - & - & 10 & 48 \\
\hline Photoresist coaters & 29 & 6 & 29 & 23 & 87 & - & - & 29 & 58 \\
\hline Exposure systems ${ }^{a}$ & 23 & 23 & 28 & 18 & 92 & 82 & - & - & 10 \\
\hline Resist developers & 10 & 5 & 18 & 36 & 69 & - & - & 46 & 23 \\
\hline Selective etchinga & 10 & 10 & 18 & 18 & 56 & - & - & 46 & 10 \\
\hline Substrate holders $b$ & 10 & 10 & 16 & 11 & 47 & - & - & 47 & - \\
\hline Substrate scribe and cut & 10 & 10 & 62 & 19 & 101 & - & - & 2 & 99 \\
\hline Resistor trim & 223 & 218 & 243 & 38 & 722 & - & - & 300 & 422 \\
\hline Wire bonders & 33 & 15 & 33 & 23 & 104 & - & - & 76 & 28 \\
\hline Eutectic die bonders & 5 & 7 & 5 & 25 & 42 & - & - & 9 & 33 \\
\hline Component attch.m/c & 33 & 28 & 20 & 15 & 96 & - & - & 51 & 45 \\
\hline Electroplate $\mathrm{m} / \mathrm{c}$ & 10 & 5 & - & - & 15 & - & - & - & 15 \\
\hline Measurement equip. \& probes & 43 & 61 & 29 & 43 & 176 & 1 & 1 & 116 & 58 \\
\hline Test equipment & 103 & 98 & 136 & 155 & 492 & 40 & - & 39 & 413 \\
\hline Insp. devices \& microscopes ${ }^{\mathrm{a}}$ & 29 & 53 & 62 & 29 & 173 & 2 & 87 & 34 & 50 \\
\hline Environmental test & 54 & 28 & 34 & 19 & 135 & - & - & - & 135 \\
\hline Package sealinga & 24 & 28 & 44 & 39 & 135 & - & - & 119 & 16 \\
\hline Leak test equipmenta & 16 & 16 & 10 & 6 & 48 & 8 & - & 35 & \\
\hline Package marking & 11 & 10 & 6 & 6 & 33 & - & - & 10 & 23 \\
\hline \multirow[t]{2}{*}{ TOTALS } & 1011 & 749 & 1060 & 795 & 3615 & 133 & 88 & 1098 & 2296 \\
\hline & \multicolumn{5}{|c|}{ Percentage of total expenditure } & 3.7 & 2.4 & 30.4 & 63.5 \\
\hline
\end{tabular}

aItems for which import level is $>66 \%$ of total usage

bItems for which import level is $>90 \%$ of total usage

In order to relate the figures in the above Tables A.1-A.6, to Figure 7 and Table VII, the following multiplication factors should be noted:

i) Ratio of received replies to total U.K. business

PWB $1: 4$

Thick film $1: 1.7$

Thin film $1: 2$

ii) Ratio of materials spent to output at sales value

PWB 1: 3

Thick film $1: 4$

Thin film $1: 3.6$ 

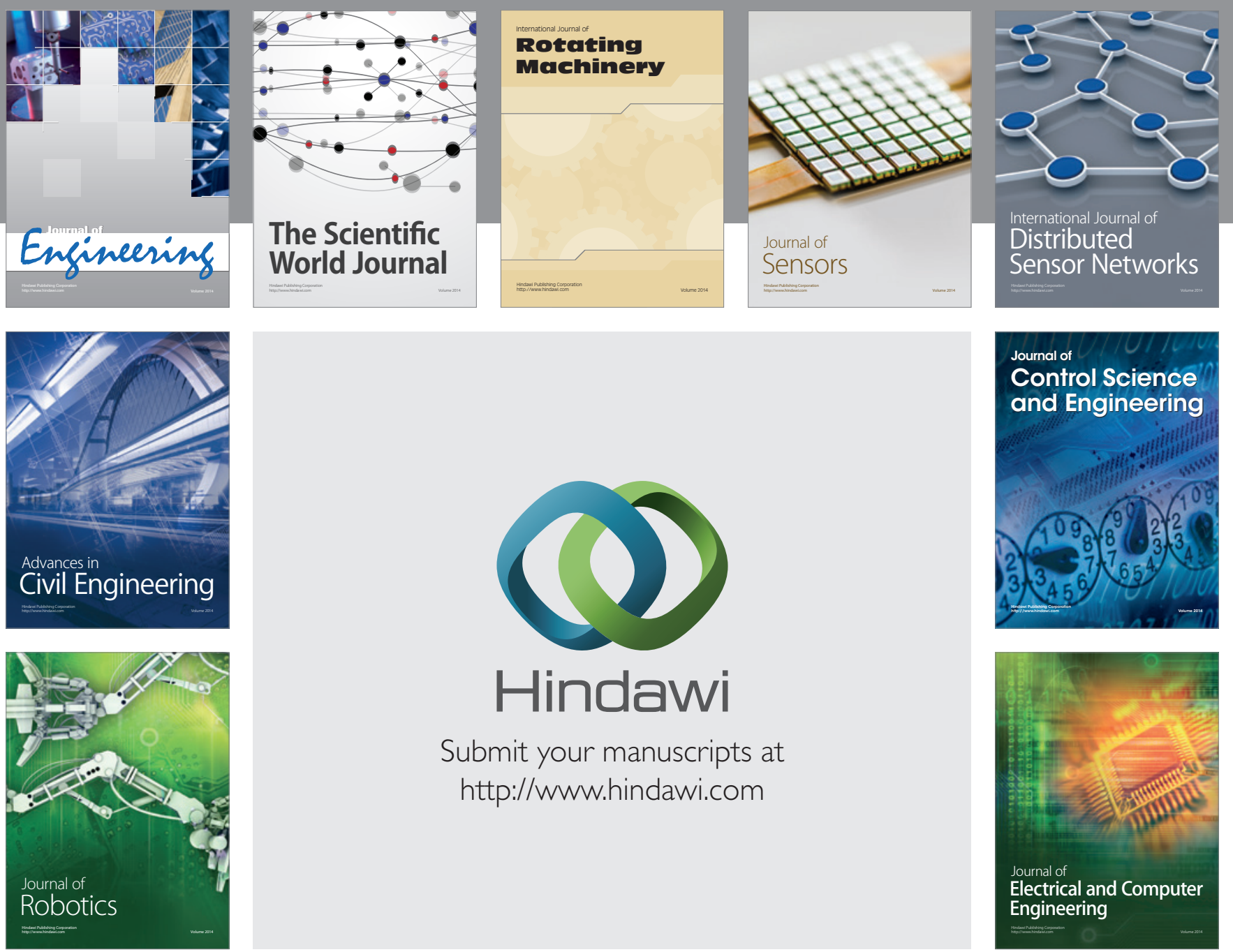

Submit your manuscripts at

http://www.hindawi.com
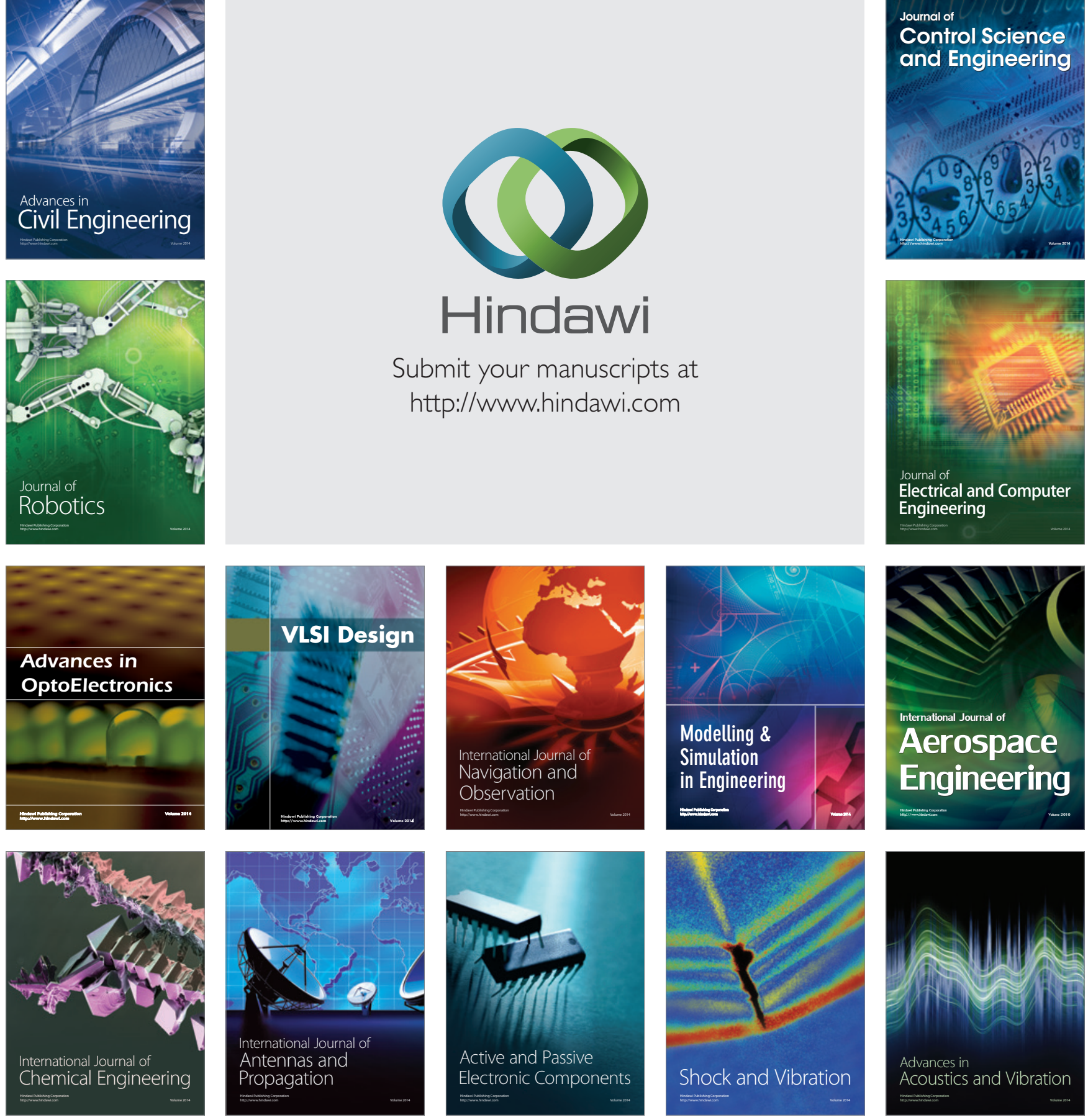